\title{
Combining high-resolution satellite images and altimetry to estimate the volume of small lakes
}

\author{
F. Baup ${ }^{1}$, F. Frappart ${ }^{2,3,4}$, and J. Maubant ${ }^{1,2,5}$ \\ ${ }^{1}$ Centre d'Études de la BIOsphère (CESBIO), UMR5126, IRD - CNES - OMP - INSU, Université de Toulouse, \\ 24 rue d'Embaquès, 32000 Auch, France \\ ${ }^{2}$ Géosciences Environnement Toulouse (GET), UMR5563, OMP, Université de Toulouse, CNRS, IRD, \\ 14 avenue Edouard Belin, 31400 Toulouse, France \\ ${ }^{3}$ Laboratoire d'Etudes en Géophysique et Océanographie Spatiales (LEGOS), UMR5566, Observatoire de Midi-Pyrénées, \\ Université de Toulouse, CNES, CNRS, IRD, 14 avenue Edouard Belin, 31400 Toulouse, France \\ ${ }^{4}$ Groupe de Recherche en Géodésie Spatiale (GRGS), France \\ ${ }^{5}$ École Supérieure des Géomètres et Topographes (ESGT), 1 boulevard Pythagore, 72000 le Mans France
}

Correspondence to: F. Baup (frederic.baup@cesbio.cnes.fr)

Received: 18 November 2013 - Published in Hydrol. Earth Syst. Sci. Discuss.: 20 December 2013

Revised: 29 March 2014 - Accepted: 14 April 2014 - Published: 27 May 2014

\begin{abstract}
This study presents an approach to determining the volume of water in small lakes $(<100 \mathrm{ha})$ by combining satellite altimetry data and high-resolution (HR) images. In spite of the strong interest in monitoring surface water resources on a small scale using radar altimetry and satellite imagery, no information is available about the limits of the remote-sensing technologies for small lakes mainly used for irrigation purposes. The lake being studied is located in the south-west of France and is only used for agricultural irrigation purposes. The altimetry satellite data are provided by an RA-2 sensor onboard Envisat, and the high-resolution images $(<10 \mathrm{~m})$ are obtained from optical (Formosat-2) and synthetic aperture radar (SAR) antenna (Terrasar-X and Radarsat-2) satellites. The altimetry data (data are obtained every 35 days) and the HR images (77) have been available since 2003 and 2010, respectively. In situ data (for the water levels and volumes) going back to 2003 have been provided by the manager of the lake. Three independent approaches are developed to estimate the lake volume and its temporal variability. The first two approaches (HRBV and ABV) are empirical and use synchronous ground measurements of the water volume and the satellite data. The results demonstrate that altimetry and imagery can be effectively and accurately used to monitor the temporal variations of the lake $\left(R_{\mathrm{ABV}}^{2}=0.98, \mathrm{RMSE}_{\mathrm{ABV}}=5 \%, R_{\mathrm{HRBV}}^{2}=0.90\right.$, and $\mathrm{RMSE}_{\mathrm{HRBV}}=7.4 \%$ ), assuming a time-varying triangu-
\end{abstract}

lar shape for the shore slope of the lake (this form is well adapted since it implies a difference inferior to $2 \%$ between the theoretical volume of the lake and the one estimated from bathymetry). The third method (AHRBVC) combines altimetry (to measure the lake level) and satellite images (of the lake surface) to estimate the volume changes of the lake and produces the best results $\left(R_{\mathrm{AHRBVC}}^{2}=0.98\right)$ of the three methods, demonstrating the potential of future Sentinel and SWOT missions to monitor small lakes and reservoirs for agricultural and irrigation applications.

\section{Introduction}

Water supply issues are creating unprecedented pressures because of increasing population and economic demands. As irrigated agriculture represents $70 \%$ of global water consumption, managing water resources is a major concern in maintaining sustainable agricultural practices. Water management will become even more relevant in the future as urbanisation, industrialisation, and climate change exert greater pressures on water use (OECD, 2012). Water resources can be monitored on a global scale using three approaches: in situ measurements, modelling, and remote-sensing observations (Jorgensen et al., 2005; Harding and Warnaars, 2011; Hall et al., 2011; Duan and Bastiaanssen, 2013). Given the 
dramatic decrease in the number of in situ gauges used in recent years and the difficulty in modelling water resources on a global scale (because of complex mixing between inflows and outflows), measuring water stages by remote sensing and especially by satellite has become a major goal in hydrology for the coming decades (The Ad Hoc Group on Global Water Datasets, 2001; Alsdorf et al., 2007; Duan and Bastiaanssen, 2013).

Satellite radar altimetry was originally developed to measure ocean surface topography accurately and has been used successfully to obtain valuable information for land hydrology by estimating the variation in lake water levels (Birkett, 1995; Cazenave et al., 1997; Crétaux et al., 2011), rivers (Birkett, 1998; Birkett et al., 2002; Frappart et al., 2006a; Santos da Silva et al., 2010), and floodplains (Frappart et al., 2006b, 2008; Santos da Silva et al., 2012). The accuracy of altimetry-based water levels can vary from 5 to $80 \mathrm{~cm}$ depending on the altimetry data used (i.e. from Topex/Poseidon and ERS-2 to Envisat and Jason-2), the size of the water bodies being flown over, the configuration of the terrain, and the presence of vegetation (Frappart et al., 2005, 2006a, b; Santos da Silva et al., 2010; Crétaux et al., 2011; Ricko et al., 2012).

However, comprehensive monitoring of surface resources also requires knowledge of the extent of the surface water and the water volume. Earth observation missions have been developed to provide images of the Earth's surface at various spatial, temporal, and spectral resolutions, which have been used to map land use and land cover dynamics over the last few decades (Kümmerle et al., 2013; Klein et al., 2014). Past (ALOS, ENVISAT), current (Formosat-2, Radarsat-2, Spot 4-5, TerraSAR-X), and future (Radarsat Constellation, Sentinel 1-2, TerraSAR-L) Earth observation missions offer high spatial resolution, frequent revisit times, and a unique opportunity to monitor the extent of global water resources, even small-sized resources. Among other applications, highresolution images were recently used to inventory tank irrigation systems in India (Abdul Hakeem and Raju, 2009), detect lake and river courses in various environments (Strozzi et al., 2012; Kharbouche and Clavet, 2013), and monitor the spatial distribution and temporal dynamics of wetlands (Zhou et al., 2010; White and Lewis, 2011).

Previous studies combined satellite observations of either water level or extent with bathymetry or in situ measurements of water storage to determine the water volume variations of lakes and inland seas. Water volumes were estimated using bathymetry and Topex/Poseidon water levels for the big Aral Sea (Crétaux et al., 2005), using in situ measurements of water storage and Topex/Poseidon water levels for Lake Dongting, China (Zhang et al., 2006). Water volume variations were determined using in situ water levels and MODIS-derived inundated areas for nine lakes in the Athabasca Delta, Canada (Smith and Pavelsky, 2009), and in situ water levels and ENVISAT-ASAR images for Lake Izabal, Guatemala (Medina et al., 2010).
Recent studies have demonstrated the potential of combining satellite imagery and radar altimetry to estimate the volume of water stored in lakes, rivers, and floodplains, and how these volumes change in response to climate variability and/or anthropogenic effects using SAR images, multispectral images, or multi-satellite observations (Frappart et al., 2005, 2006b, 2008, 2012; Yesou et al., 2007; Ding and Li, 2011; Haibo et al., 2011; Duan and Bastiaanssen, 2013). Despite the relevance of these results, these techniques have not been applied yet to study small lakes due to the difficulty in collecting synchronously radar altimeter data, highresolution images and consistent ground data. No information is thus available about the limits of the remote-sensing technologies for small lakes, contrary to great lakes (Birkett, 1995; Cazenave et al., 1997; Crétaux et al., 2005, 2011; Zhang et al., 2006; Medina et al., 2010), which is a strong limitation for taking full advantage of the future satellite missions (Sentinel-1/2, Jason CS, Radarsat Constellation, Swot). Lake La Bure offers a unique opportunity to apply these techniques over a well-monitored small lake.

This study proposes three different methods to estimate water volume and water volume changes in lakes using highresolution imagery, satellite altimetry and/or in situ measurements. Our goal is to demonstrate the feasibility of these techniques over small lakes $(<100 \mathrm{ha})$. The methods are used to determine the variations in the volume of Lake La Bure, a small reservoir (with an average area of 52 ha) located in an irrigated agricultural area in the south-west of France). Although this study is limited to a single example because of the sparse cover of current altimetry tracks and the lack of in situ observations on other lakes to validate the approaches presented below, it shows what can be achieved with current altimetry missions. The paper is structured as follows: the primary characteristics of the study site, satellite data, and in situ data are presented in Sect 2. In Sect. 3, the three different methods are presented for estimating the water volume of the lake. The first two consist in relating either lake area derived from satellite images or altimetry-based water levels in combination with in situ estimates of water levels and volumes to determine the water volume of the lake. They are respectively named HRBV (high-resolution image-based volumes) and ABV (altimetrybased volumes). The third one, named AHRBVC (altimetryand high resolution-based volume changes), is based on the combination of information on the lake area derived from satellite images and altimetry-based water levels to estimate water volume changes. No ground data are used in the third method (except for validation). The results are analysed and discussed in Sect. 4, in which the HR images, altimetry, and a combination of the two techniques is used to estimate accurately seasonal changes in the water volume. Concluding remarks and future work are presented in Sect. 5. 

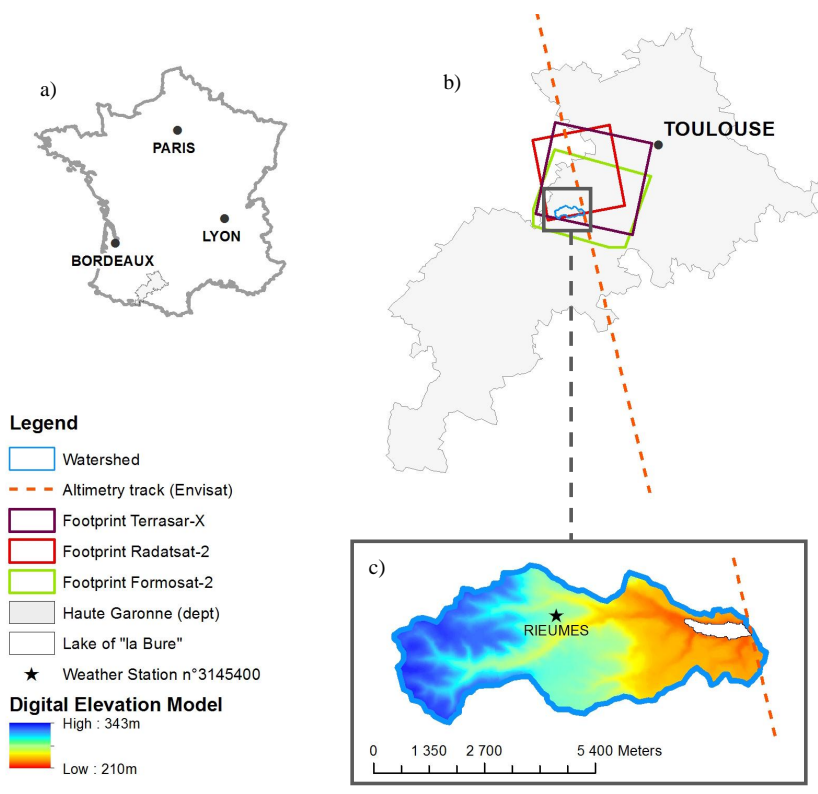

Figure 1. Lake La Bure is located in the southwest of France $40 \mathrm{~km}$ southwest of Toulouse, in the department of Haute Garonne (a), within the footprint of TERRASAR-X (purple empty rectangle), RADARSAT-2 (red empty rectangle), and FORMOSAT-2 (green empty rectangle), and under ENVISAT RA-2 altimetry track 773 (orange dashed line) (b). The weather station (black star) and the lake (in white) are presented inside the watershed, superimposed onto the digital elevation model (c).

\section{Study area and data sets}

\subsection{Study area}

Lake La Bure $\left(43^{\circ} 24^{\prime} 54^{\prime \prime} \mathrm{N} ; 1^{\circ} 09^{\prime} 07^{\prime \prime} \mathrm{E}\right)$ is located in the southwest of France, close to the city of Rieumes (which is $40 \mathrm{~km}$ southwest of the city of Toulouse), in a study area monitored by CESBIO in the framework of the Sud-Ouest project (Dejoux et al., 2012; Baup et al., 2012, Fieuzal et al., 2012, 2013) (Fig. 1). The area has a temperate climate with a mean annual rainfall of approximately $600 \mathrm{~mm}$. Rainfalls are regularly distributed (with a monthly mean of $50 \mathrm{~mm}$ ), with a maximum of $80 \mathrm{~mm}$ in the spring and a minimum of $32 \mathrm{~mm}$ in the summer according to the records from meteorological station no. 3145400 of Météo-France, the French Meteorological agency (http://www.meteofrance.fr). Inside the watershed (2070 ha) of the lake, the relief is not clearly delineated $(\min =0 \%, \max =16.9 \%$, and mean slope $=2.8 \%)$, and the land use is composed of crops $(40.90 \%)$, forest $(24.02 \%)$, grassland $(33.4 \%)$, and water bodies $(1.68 \%)$. Lake La Bure is an artificial reservoir that was constructed in 1987 for crop irrigation purposes. Since its construction, the barrage has been managed by the SIAH (Syndicat Intercommunal d'Aménagement Hydraulique de la vallée du Touch et de ses affluents) company. The extent of the lake can reach $52 \mathrm{ha}$ for a maximum water volume of $4.1 \mathrm{hm}^{3}$.

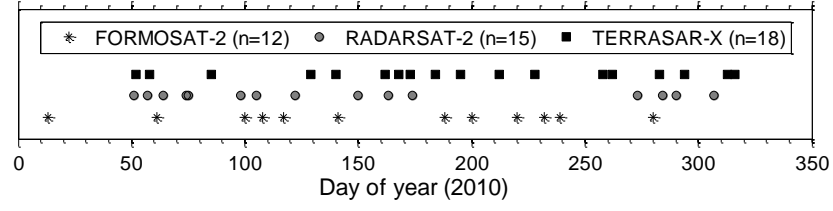

Figure 2. Timeline for acquisition of high spatial resolution satellite images in 2010 (Formosat-2, Radarsat-2, Terrasar-X).

The charge and discharge of the lake only occur via rainfall events (throughout the year) and irrigation pumping (primarily in the summer). The lake is located under Envisat RA-2 altimetry track 773 and is inside the footprint of three high-resolution images that are acquired by the Formosat-2, TerraSAR-X, and Radarsat-2 satellites.

\subsection{Satellite data}

The satellite data used in this study were composed of HR images and altimetry data. Forty-five HR images were acquired in 2010, between January and November, by sensors onboard three different low-orbiting satellites (Radarsat2, TerraSAR-X, and Formosat-2) (Fig. 2). Thirty-three of these images were acquired in the microwave domain using SAR instruments (Radarsat- 2 and TerraSAR-X), and twelve were acquired using the multispectral mode of the Formosat2 satellite. The altimetry data were acquired by the Envisat RA-2 sensor between February 2002 and October 2010.

\subsubsection{SAR images}

The SAR images were acquired at X- and C-bands by TERRASAR-X and RADARSAT-2, respectively (Table 1).

TerraSAR-X is a German Earth observation satellite that was launched in June 2007 (Fritz et al., 2008; Breit et al., 2010). The SAR instrument onboard the satellite operates in the X-band $(f=9.65 \mathrm{GHz}$ and $\lambda=3.1 \mathrm{~cm})$. All of the images (which numbered 18 in 2010) were provided by the German Aerospace Centre (DLR) and were acquired with the same polarisation state $(\mathrm{HH})$ for incidence angles ranging from 27.3 to $53.3^{\circ}$ to increase the repetitiveness of observations from an initial 11-day orbital cycle. Two acquisition modes were combined: StripMap (SM) and SpotLight (SL), which were characterised by pixel spacings of approximately 3 and $1.5 \mathrm{~m}$, respectively. The backscattering coefficients were calculated using Eq. (1) (Lavalle and Wright, 2009):

$\sigma_{p q}^{0}=20 \log \left(\mathrm{DN}_{p q}\right)+10 \log \left(\mathrm{CF}_{p q}\right)+10 \log (\sin (\sigma))$,

where DN denotes the digital number of pixels, CF denotes the calibration factor, and $\theta$ denotes the incidence angle. The indexes $p$ and $q$ denote the linear polarisation states of the electromagnetic waves $(\mathrm{H}$ or $\mathrm{V})$, respectively.

The Canadian satellite Radarsat-2 was launched in December 2007 (Morena et al., 2004). Its payload encompasses 
Table 1. Main characteristics of optical and microwave sensors. The given information is relative to the antenna (frequency, mode, polarisation states, range of incidence angles) and the satellite (orbital cycle).

\begin{tabular}{llllrrr}
\hline Satellite & Frequency / wavelength & Mode & Polarisation states & $\begin{array}{r}\text { Range of } \\
\text { incidence angle }\end{array}$ & $\begin{array}{r}\text { Orbital cycle } \\
\text { sampling }\end{array}$ \\
\hline Radarsat-2 & C-band $(f=5.405 \mathrm{GHz})$ & FQ & HH, VV, VH, HV & 23 to $41^{\circ}$ & 24 days & $5 \mathrm{~m}$ \\
Terrasar-X & X-band $(f=9.65 \mathrm{GHz})$ & SL/SM & HH & 27 to $53^{\circ}$ & 11 days & $1.5 \mathrm{~m}(\mathrm{SL})$ \\
$3 \mathrm{~m}(\mathrm{SM})$ \\
Formosat-2 & $\lambda: 0.44-0.90 \mu \mathrm{m}$ & Multi-spectral & - & $\pm 45^{\circ}$ & 1 day & $8 \mathrm{~m}$ \\
\hline
\end{tabular}

a SAR instrument operating in the C-band $(f=5.405 \mathrm{GHz}$ and $\lambda=5.5 \mathrm{~cm}$ ). The orbital cycle of the satellite is 24 days, but different orbit and incidence angles can be combined to increase the number of possible acquisitions per cycle. The images (which numbered 15 in 2010) were provided by the Canadian Space Agency through the SOAR (Science and Operational Application Research) programme and were all acquired in quad-polarisation mode (Fine Quad-Pol: HH, $\mathrm{VV}, \mathrm{HV}$, and $\mathrm{VH})$. The incidence angles ranged from $23^{\circ}$ (FQ5) to $41^{\circ}$ (FQ21) with a pixel spacing of $5 \mathrm{~m}$. The images were calibrated using NEST software (NEST, 2013) and Eq. (2) (Skriver et al., 1999):

$\sigma_{i}^{0}=20 \log _{10}\left(\mathrm{DN}_{i} / \mathrm{A} 2_{i}\right)+10 \log _{10}\left(\sin \left(\theta_{i}\right)\right)$,

where $\mathrm{DN}_{i}$ denotes the digital number of the pixel $i, \theta$ denotes the incidence angle, and A2 denotes the gain (which is provided by the image product data table).

All of the SAR images were geo-referenced using aerial IGN ortho-photos (with a spatial resolution of $50 \mathrm{~cm}$ ). The ortho-photos were first resized to the resolution of the image and then 70 reference points were taken between the base (IGN ortho-photos) and wrap images (satellite data). The geo-location accuracy was under 2 pixels (i.e. 3 to $6 \mathrm{~m}$ ) on average for the different products. Finally, all of the radar images were filtered to reduce speckle effects using a gamma filter with a filtering window of 6 by 6 pixels.

\subsubsection{Optical images}

The optical images (12) were provided by the Taiwanese Formosat-2 satellite (which was launched in 2004) for four narrow wavelengths between 0.45 and $0.90 \mu \mathrm{m}$ corresponding to the blue, green, red, and near-infrared ranges (Liu, 2006; Chern et al., 2008, Table 1). All of the images used in this study were acquired in multispectral mode (MS) with a theoretical daily orbital cycle (sun-synchronous orbit) at the same viewing angle $\left( \pm 45^{\circ}\right)$. This mode was characterised by a spatial resolution of $8 \mathrm{~m}$ for a scene coverage of $24 \mathrm{~km} \times 24 \mathrm{~km}$. All of the images were processed by French company CS, Systèmes d'information in the framework of the Kalideos project (http://kalideos.cnes.fr). They were ortho-rectified using CNES ortho-rectification tools. Cloud detection and atmospheric correction were also applied (Sand and De Boissezon, 2006; Hagolle et al., 2010).

\subsubsection{Altimetry data}

RA-2 (Advanced Radar Altimeter) is a nadir-looking pulselimited radar altimeter onboard ENVISAT that operates at two frequencies: the Ku-band $(13.575 \mathrm{GHz} /$ wavelength of $2.3 \mathrm{~cm})$ and the S-band $(3.2 \mathrm{GHz} / 9.3 \mathrm{~cm})$ (Zelli, 1999). The geophysical data records (GDRs) distributed by ESA (ESA, 2002) include accurate satellite positions (i.e. the longitude, latitude, and altitude of the satellite in its orbit) and timing, altimeter ranges, instrumental, propagation, and geophysical corrections applied to the range, and several other parameters used to build altimetry-based water levels. The alongtrack resolution of Envisat RA-2 is around $350 \mathrm{~m}$ in highfrequency mode.

For the ENVISAT mission, four different retracking algorithms are operationally applied to raw RA-2 data to provide range estimates and backscattering coefficients. Each retracking algorithm, namely Ocean, Ice-1, Ice-2, and Sea-Ice, has been developed for a specific type of surface, but none of these algorithms has been specifically designed for processing altimeter echoes over land (Brown, 1977; Wingham et al., 1986; Laxon, 1994; Legrésy and Rémy, 1997). Previous studies have shown that the Ice-1 algorithm measures the water levels of small lakes and reservoirs, rivers, and floodplains most accurately (Frappart et al., 2006a; Santos da Silva et al., 2010; Ricko et al., 2012). In this study, the altimetry measurements contained in the ENVISAT RA-2 GDRs were made available by the Centre de Topographie des Océans et de l'Hydrosphère (CTOH - http://ctoh.legos.obs-mip.fr/) for February 2002 to October 2010 (cycles 8 to 93), corresponding to the reference repetitive orbit of the satellite.

\subsection{In situ data}

The monthly rainfall data came from the records of weather station no. 3145400 , which is located less than five kilometres from the centre of the lake and is operated by the French Meteorology Agency (Météo France). The relationship between the water levels and the volume of water stored in the lake was established in 1987 when the lake was dug (Fig. 3). More recent information on the storage capacity of the lake is available from bathymetric surveys that were performed in 2010 by AEAD (Agence de l'Eau Adour-Garonne, which depends on the Ministry of Ecology, Sustainable Development, 
Table 2. Summary of ground data used (abacus of the lake, bathymetric draw, water level and rainfall). Available periods and sampling frequencies of acquisitions are given.

\begin{tabular}{lrr}
\hline Ground data & $\begin{array}{r}\text { Available } \\
\text { period }\end{array}$ & $\begin{array}{r}\text { Sampling } \\
\text { frequency }\end{array}$ \\
\hline Lake calibration & & \\
function (abacus) & In 1987 & - \\
Bathymetric draw & In 2010 & - \\
Water level & $2003-2010$ & Weekly \\
Rainfall & $2003-2010$ & Daily \\
\hline
\end{tabular}

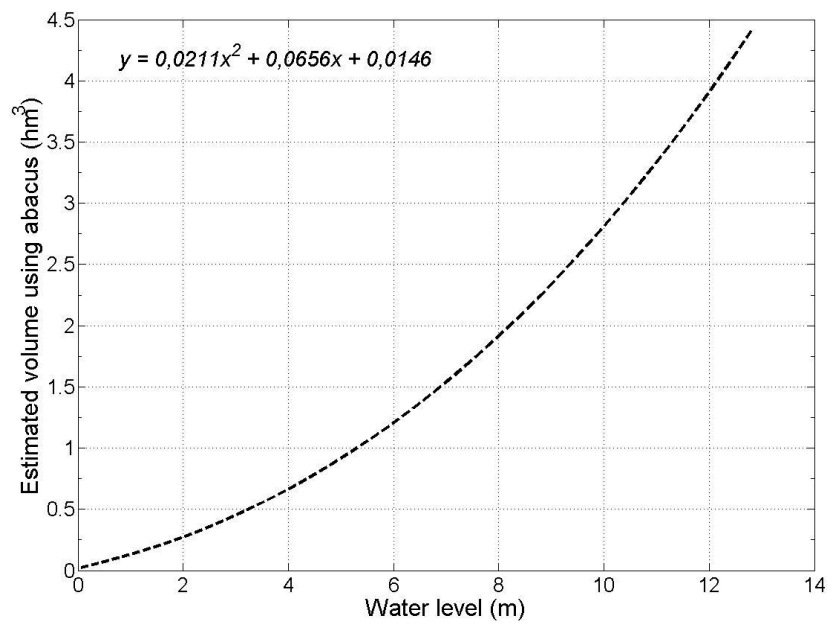

Figure 3. Relationship between in situ water levels and the volumes of Lake La Bure established in 1987 (abacus of the lake).

and Energy). The water levels were recorded at two different time steps, pressure probes were used to obtain automatic weekly measurements, and monthly data were provided by gauge readings. Figure 4 shows the temporal variation in the volume of water stored in Lake La Bure over the study period. The volume ranged between 1.5 and $4.1 \mathrm{hm}^{3}$ and describes an annual cycle with alternation of filling and emptying phases. The water level can not rise further than $4.1 \mathrm{hm}^{3}$ due to a spillway effect. The difference between the volume obtained from the in situ water levels and the volume obtained from the bathymetric survey performed in 2010 was less than $2 \%$. This difference was attributed both to the accuracy of the bathymetric measurements and to possible siltation. Various characteristics of the available ground data are summarised in Table 2.

\section{Methodology}

Figure 5 summarises the methods used to monitor the water volume of Lake La Bure. The satellite data acquired within the optical and microwave regimes were processed to estimate the water surfaces (using HR images) and levels (us-

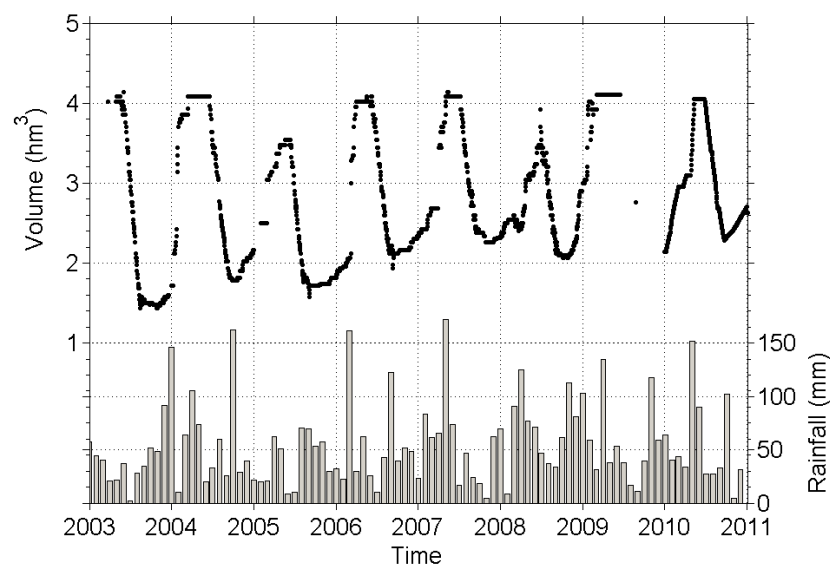

Figure 4. Temporal variations in the local rainfall (vertical grey bars) and measured water volume of Lake La Bure (black dots) from 2003 to 2011.

ing altimetry) throughout the hydrological cycle. The temporal variation in the volume of the lake (HRBV and $\mathrm{ABV}$ methods), or in the volume change (AHRBVC method), was finally estimated by combining one type of satellite data (HR images or radar altimetry) with ground measurements or using two types of complementary satellite data.

\subsection{Determination of the extent of the lake area from satellite imagery}

An automatic parallelepiped classification was performed using ENVI software on each HR image to determine which pixels could be associated with open water (Richards, 1999; ENVI, 2004; Lillesand et al., 2008). This supervised classification method relied on a simple logical rule to classify a given pixel based on its radiometry (four channels are considered: blue, green, red, and near infra-red). The decision boundaries formed a four-dimensional parallelepiped in the image data space. Each class was defined in terms of a threshold for the standard deviation from the mean of each training site (i.e. the region of interest). Four classes were identified as being representative of the landscape: forests, open water, bare soils, and crops. Once the classification process was completed, all of the surface elements that were identified as open water were vectorised and exported to an ArcGIS shape file format in which the boundary represented the lake shoreline (artifacts in the polygon that represented open water were suppressed using the FillHoles toolbox of the software). Figure 6 shows the temporal variations in the lake shoreline for four different dates in 2010 that were acquired by the Radarsat-2 satellite. 


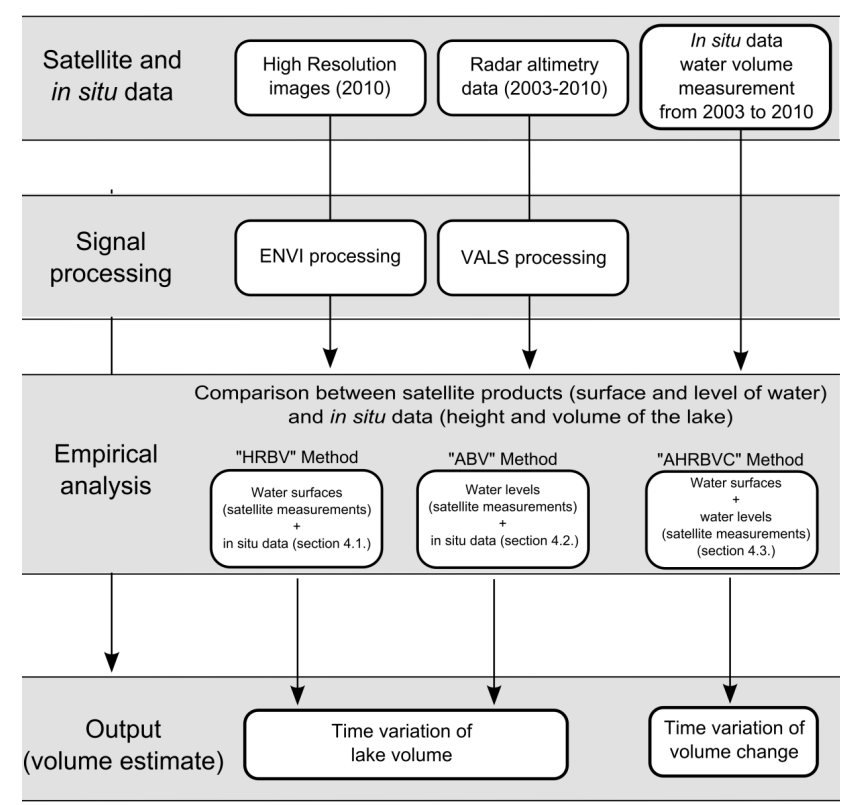

Figure 5. Flowchart showing the processing steps used to estimate the volume of Lake La Bure using high-resolution images (HR), radar altimetry (RA-2), and ground data for each of the three methods (HRBV, ABV and AHRBVC).

\subsection{Altimetry-based water levels}

The principle behind radar altimetry is as follows: the altimeter emits a radar pulse and measures the two-way travel time from the satellite to the surface. The distance between the satellite and the Earth's surface - the altimeter range $(R)$ is thus derived with a precision of a few centimetres. The satellite altitude $(H)$ with reference to an ellipsoid is also accurately known from orbitography modelling. Taking into account propagation delays from the interactions of electromagnetic waves in the atmosphere and geophysical corrections, the height of the reflecting surface $(h)$ with reference to an ellipsoid or a geoid can be estimated as follows:

$$
\begin{aligned}
h & =H-R-C_{\text {ionosphere }}-C_{\text {dry troposphere }}-C_{\text {wet troposphere }} \\
& -C_{\text {solid Earth tide }}-C_{\text {pole tide }}
\end{aligned}
$$

where $C_{\text {ionosphere }}$ is the correction for delayed propagation through the ionosphere, $C_{\mathrm{dry}}$ troposphere and $C_{\text {wet troposphere }}$ are corrections for delayed propagation in the troposphere from pressure and humidity variations, respectively, and $C_{\text {solid Earth tide }}$ and $C_{\text {polar tide }}$ are corrections that account for crustal vertical motions from the solid and polar tides, respectively.

An altimetry station, which is the equivalent of an in situ water level gauge, can be defined at each intersection between a lake, river, or floodplain and the satellite ground track. For each altimeter pass or cycle, the altimetry measurements are processed using the following three primary steps to obtain a water level: a 2-D selection is made from

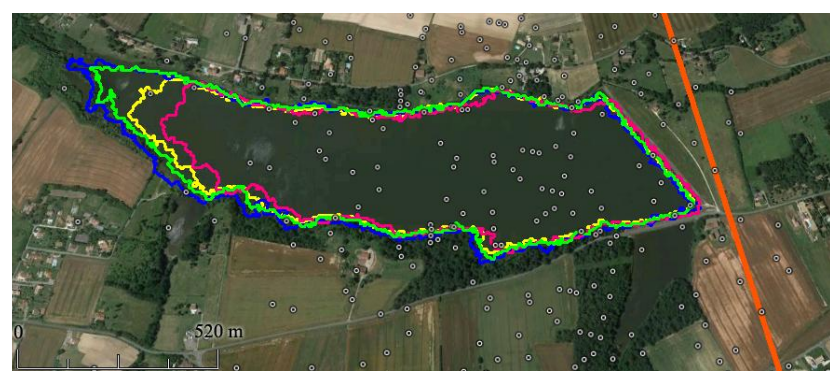

Figure 6. Examples of temporal evolution of the lake shorelines resulting from the supervised classification of Radarsat- 2 images: the green, blue, yellow, and pink lines represent the lake shoreline on 31 July, 23 June, 11 October, and 30 September 2010, respectively; the orange line to the east of the lake represents the theoretical ground track of the Envisat altimeter. The black and white dots represent $20 \mathrm{~Hz}$ altimetry measurements over the lake in 2010 .

the data contained in the window corresponding to the altimetry station using satellite imagery; the altimetry heights from Eq. (3) are filtered (at varying degrees of complexity depending on the approach chosen) using a statistical and/or hydrological criterion; and the altimetry-based water level is computed using estimates of either the median or the mean of the selected altimetry heights, which may or may not have been corrected for hooking effects (Frappart et al., 2006a; Santos da Silva et al., 2010). This process is repeated for each cycle to construct a water level time series at the altimetry station. In this study, Virtual ALtimetry Station (VALS) software was used to derive the time series of water levels for Lake La Bure from ENVISAT RA-2 data from February 2002 to October 2010. The processing of altimetry data using VALS consisted of four primary steps:

1. A coarse selection of the altimetry data over the water body contained in a polyline using Google Earth was obtained.

2. The VALS visualisation tool was used to obtain a refined selection of the valid altimetry-derived water levels in which outliers were removed and the hooking effects were likely to be corrected for.

3. valid water levels were identified as they exhibit lowlevel variations (typically of a few centimetres) between the shores of the lake (Fig. 7). During low water periods, only one valid water level may likely to be found. Due to the few valid points present in each cycle, from one to five, no specific processing to remove hooking effects was applied.

4. The time series of water levels was computed using the median value of all of the valid altimetry-based water levels for each cycle.

When a water body is encompassed in the footprint, the signal received by the altimeter is dominated by the presence of 


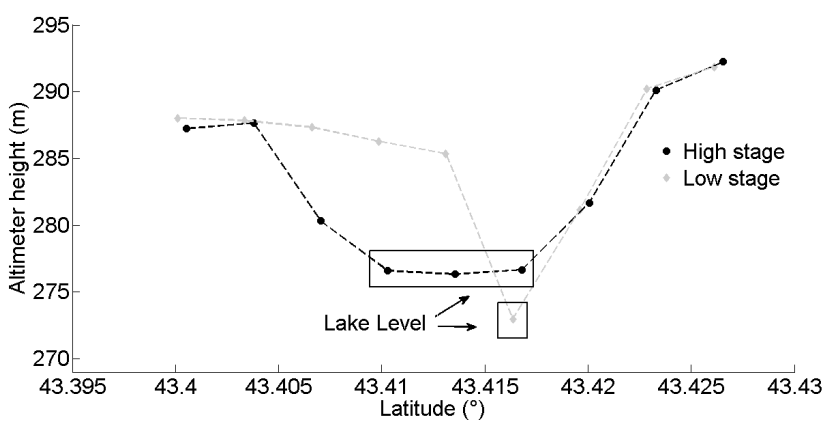

Figure 7. Along-track evolution of the altimeter height over Lake La Bure and its surroundings. Two cases are presented, corresponding to the high and low stages of the lake.

water (Michailowsky et al., 2012). The corresponding radar echo or waveform has a specular shape. The signature of vegetation could be eventually identified by the presence of secondary maxima in the trailing edge (Calmant et al., 2008). This allows the retrieval of reliable water levels even for rivers of widths less than $300 \mathrm{~m}$ under a forest cover (Frappart et al., 2005, 2006b; Santos da Silva et al., 2010, 2012; Michailowsky et al., 2012). Due to the small dimensions of the lake, VALS allowed us to pick up manually the valid measurements using its selection tool as presented in Fig. 7. Further details on processing the altimetry data using VALS software can be found in Santos da Silva et al. (2010). At the end of the process, 67 valid water levels were estimated, which corresponds to $77 \%$ of all the available altimetry cycles. All water levels are given with reference to the WGS84 ellipsoid and presented as a relative value of water level.

\subsection{Lake volume estimates}

Three independent approaches were developed to estimate the lake volume and its temporal variability. In the first two methods (HRBV and ABV), an empirical relationship between either the lake surface derived from the HR images or altimetry-based water levels and quasi-synchronous estimates of the lake volume was determined from the in situ water level measurements. In the third method (AHRBVC), the lake surface from the HR images was combined with altimetry-based water levels that were acquired quasi synchronously. A combination of satellite products was used to estimate the change in the lake volume from both the variation in the water level and the surface. To this end, the lake of interest was modelled as a simple geometric shape, for which the variation in the water volume $(\Delta V)$ between two dates $\left(t_{1}\right.$ and $t_{2}$, respectively) was computed using Eq. (4), similar to the second method proposed by Taube (2000):

$\Delta V=S(t 1) *|\Delta H|+\operatorname{sgn}(\Delta H) *(|\Delta S| *|\Delta H|) / 2$,

where $\Delta H=H(t 2)-H(t 1)$ and $\Delta V=V(t 2)-V(t 1)$ denote the difference in the water levels $(H)$ and the volume

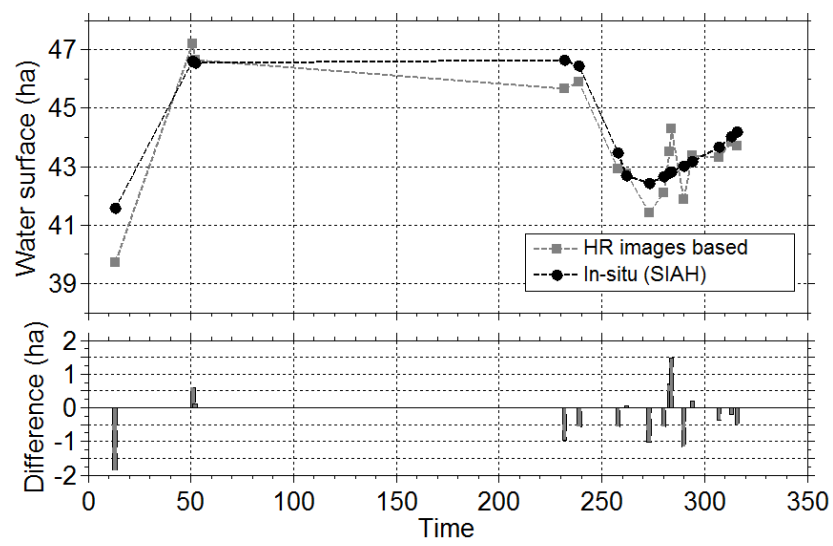

Figure 8. Comparison between satellite-estimated and bathymetry time series of the water surface of lake La Bure in 2010. Bathymetry data are only available for the water surface ranged between 0 and 47 ha. No satellite data (HR image based) outside of this range are therefore presented.

between two dates, $t 1$ and $t 2$, respectively. $\Delta=S(t 2)-S(t 1)$ denotes the variation in the surface between the two dates.

A triangular geometric shape was chosen to reflect the volume changes as a function of the variations in both surface $(\Delta S)$ and height $(\Delta H)$ between $t 1$ and $t 2$. The ratio between $\Delta S$ and $\Delta H$ characterises the slopes of the lake shores and permits the reproduction of the changes in regime that occur during the lake's filling and emptying phases.

\section{Results and discussion}

\subsection{Estimating the lake volume using HR images - HRBV method}

The satellite water surfaces derived from HR images were validated using in situ surfaces estimated by bathymetric measurements in 2010 (for which the surfaces have been estimated for each satellite overpass in the domain of validity of the bathymetry data, from 0 to $47 \mathrm{ha}$ ). Results, presented in Fig. 8, show that the water surfaces estimated from satellites and from bathymetry are strongly correlated $\left(R^{2}=0.83\right)$. Differences never exceed 1.8 ha, which represents a maximum relative root mean square error (RRMSE) of $4.3 \%$.

Figure 9 shows the temporal evolution of the water surface of Lake La Bure for the complete series of $45 \mathrm{HR}$ images that were acquired in 2010 . The lake surface was estimated by applying the method presented in Sect. 3.1 to the Formosat2, Radarsat-2, and TerraSAR-X images that were acquired in 2010. The measurement of the temporal behaviour of the lake surface from the three sensors was highly consistent and ranged from 42 to $52 \mathrm{ha}$. The difference between the three estimates never exceeded 3.94 ha $(\mathrm{RRMSE}=8.5 \%)$ and equalled 0.51 ha (which was $1.1 \%$ of the mean water surface) when averaged over the complete period of observation 


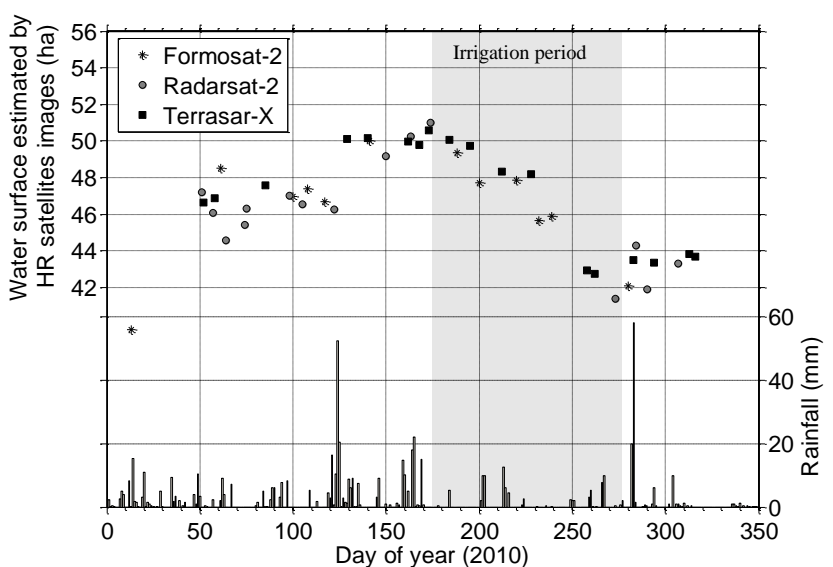

Figure 9. Temporal evolution of the water surface of Lake La Bure, as estimated by HR satellite images in 2010, superimposed with daily rainfall events (TerraSAR-X data are shown as black squares, Radarsat- 2 as a grey circle, Formosat-2 as black stars and the irrigation period as a grey rectangle).

for the quasi-synchronous satellite acquisitions (i.e. time lags below five days).

The annual cycle of the open water surface consists of two phases: the filling of the lake (from the end of September to mid-June) and the emptying of the lake (during the summer). The filling of the lake only occurs through rainfall events (primarily from runoff inside the watershed). The lake surface significantly increases over this period. No additional pumping is needed to fill the lake more rapidly, unlike some of the other lakes in the region studied. The lake empties during the irrigation period, which occurs between July and October (Fig. 9). In the summertime, the low amount of rainfall is not sufficient to compensate for losses from irrigation and evaporation.

Figure 10 shows an empirical relationship between the estimates of the lake surface from the HR images and in situ volume measurements (interpolated daily). The relationship is clearly non-linear (i.e. a second-order polynomial function) with a coefficient of determination of 0.90 and a mean error of $0.200 \mathrm{hm}^{3}$ for the volume estimates (i.e. $7.4 \%$ of the average water volume in 2010). In agreement with the bathymetric measurements, the surface changed dramatically (from 40 to 44 ha) for small volume changes between 2.2 and $2.5 \mathrm{hm}^{3}$ when the filling began (sensitivity of $0.080 \mathrm{hm}^{3} \mathrm{ha}^{-1}$ ). The relationship is fairly linear for volume changes from $2.5 \mathrm{hm}^{3}$ to greater than $4 \mathrm{hm}^{3}$, with a higher sensitivity compared to the beginning of the filling phase $\left(0.237 \mathrm{hm}^{3} \mathrm{ha}^{-1}\right)$.

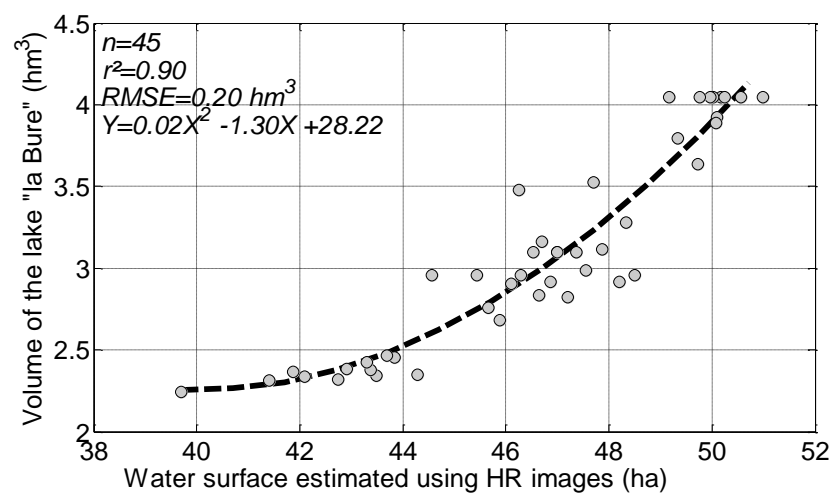

Figure 10. Empirical relationship between surface products (from HR satellite images) and measured volume (SIAH). Volumes are daily interpolated from weakly measurements.

\subsection{Estimating the lake volume from altimetry - ABV method}

\subsubsection{Validation of altimetry-based water levels}

The altimetry data (RA-2) were validated by directly comparing the altimetry-based water levels with the in situ water levels from gauge measurements made by the Lake Management Institute (SIAH) over the 2003-2010 period (Fig. 11). Similar temporal variations were observed for both data sets, in which the in situ water levels exhibited annual (peak-topeak) amplitudes between $2.65 \mathrm{~m}(2007 / 2008)$ and $5.36 \mathrm{~m}$ (2003/2004). Both the seasonal variations (i.e. the maxima from May to June and the minima from September to October) and the inter-annual variations (i.e. the minimum during the drought of 2003) were also successfully detected. Although the difference between the in situ and altimetryderived water levels reached $0.75 \mathrm{~m}$ one time, it did not exceed $0.3 \mathrm{~m}$ in $77 \%$ of the cases studied. The RMSE and $R^{2}$ were equal to $0.27 \mathrm{~m}$ and 0.99 , respectively, showing that the two sources of data were in very good agreement. The results obtained in this study were comparable to results for large lakes (Crétaux and Brikett, 2006; Ricko et al., 2012; Duan and Bastiaanssen, 2013) and large rivers (Frappart et al., 2006a; Santos da Silva et al., 2010) and were better than those obtained for various small rivers (Santos da Silva et al., 2010).

\subsubsection{Pluri-annual water volume estimates}

Figure 12 shows the empirical relationship that was obtained between the ground-measured volumes and the altimetryderived water levels. Sixty-five measurements were used from the period between 2003 and 2010 to obtain a secondorder polynomial that related the altimetry-based water levels to the water volume stored in the lake. The statistical parameters highlighted the quality of the regression $\left(R^{2}=0.98, \operatorname{RMSE}=0.12 \mathrm{hm}^{3}\right.$, and $\left.\mathrm{RRMSE}=5 \%\right)$. 


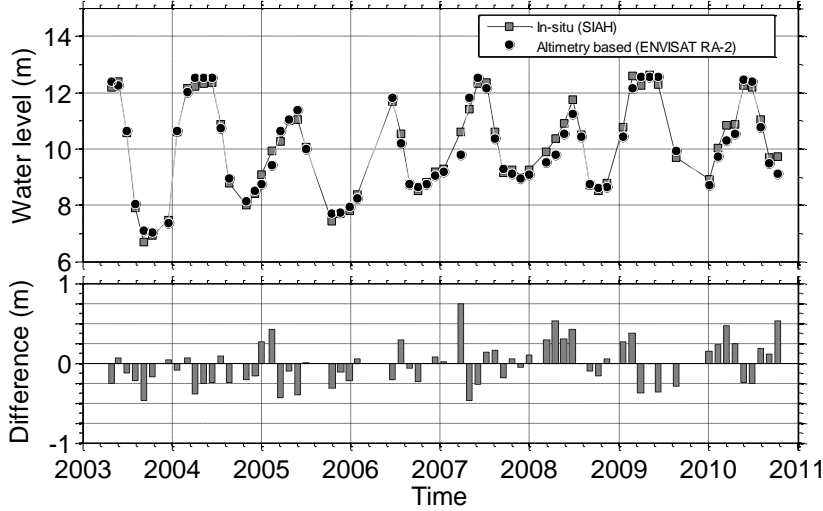

Figure 11. Comparison of satellite-estimated (RA-2) and groundmeasured (SIAH) time series of the water level of Lake La Bure from 2003 to 2010. Differences between altimetry-based and in situ water levels are given in the lower panel.

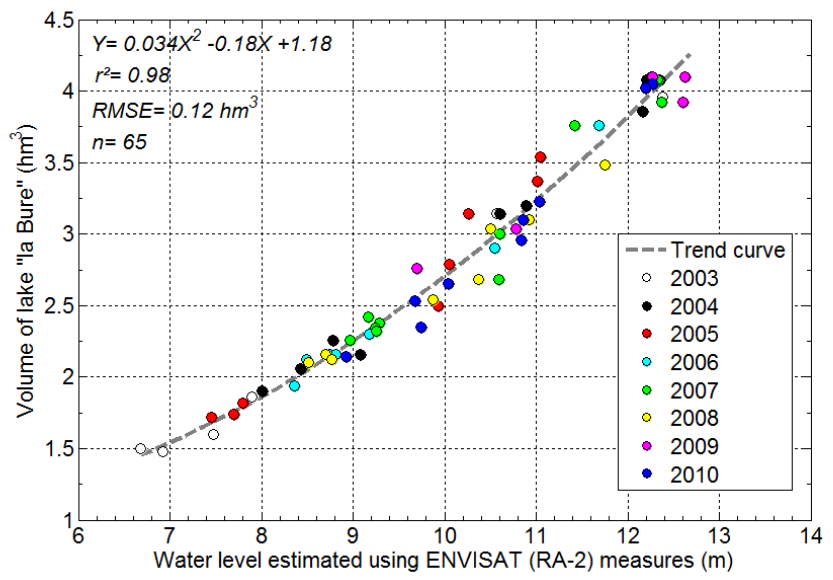

Figure 12. Empirical relationship between the satellite water level (RA-2) and the measured (SIAH) water volume of Lake La Bure from 2003 to 2010. Each year is colour separated.

No yearly dependence was observed, confirming the temporal stability of the method. Moreover, the trend curve obtained from altimetry data over the period 2003-2010 is similar to the relationship given by the abacus of the lake performed in 1987 (Fig. 3), confirming the relevance of this satellite approach.

For subsequent comparison with the HR images, a specific empirical relationship relating altimetry-based water levels to water volumes was determined for 2010 (Sect. 4.3). Figure 13 compares the water volumes that were estimated using these two relationships. The results were very similar, although the results obtained using the empirical function that was determined using over 8 years of altimetry data were slightly more accurate than those obtained using the empirical function for 2010 (Table 3). The lake RMSE never exceeded $0.17 \mathrm{hm}^{3}$ and corresponded to a high coefficient of

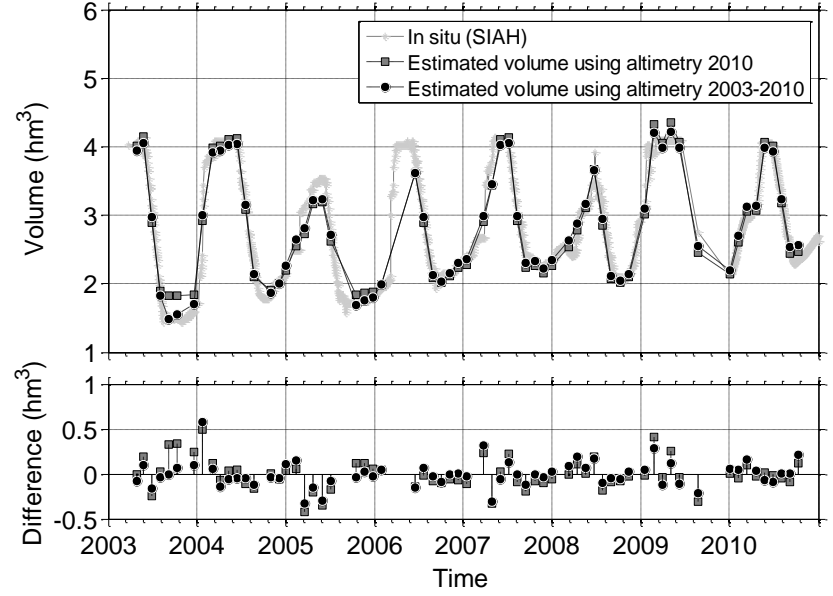

Figure 13. Comparisons between the temporal evolution of the water volume of Lake La Bure, estimated using two calibration functions: annual for 2010 (grey square) and over the period 2003-2010 (black dots). In situ volumes are represented by a light grey star. The differences between these results and the in situ measurements are shown in the lower panel.

Table 3. Evaluation of the yearly dependence of the calibration function used to estimate the lake 1 volume from the water level measured by the altimeter (RA-2). Two calibration functions were considered: annual (2010) and pluri-annual (2003-2010).

\begin{tabular}{lrrrr}
\hline $\begin{array}{l}\text { Period of the estimated } \\
\text { calibration function }\end{array}$ & $\begin{array}{r}\text { Number of } \\
\text { points }\end{array}$ & $R^{2}$ & $\begin{array}{r}\text { RMSE } \\
\left(\mathrm{hm}^{3}\right)\end{array}$ & $\begin{array}{r}\text { RRMSE } \\
(\%)\end{array}$ \\
\hline 2010 & 65 & 0.96 & 0.17 & 6.4 \\
$2003-2010$ & 65 & 0.98 & 0.12 & 5.0 \\
\hline
\end{tabular}

determination $\left(R^{2} \geq 0.96\right)$ and a low relative error (i.e. the mean lake volume had an RRMSE of $6.4 \%$ ).

\subsection{Combined use of HR images and altimeter data - AHRBVC method}

In this section, we show how variations in the lake volume were obtained by combining the HR images (Sects. 2.2.1 and 2.2.2) with the altimetry-derived water levels (Sect. 2.2.3). This approach was validated for 2010 , for which satellite images and altimetry data were simultaneously available for comparison with in situ measurements of the lake volume. Figure 14 shows the temporal variations in the lake volume that were estimated using three different methods: ground measurements (SIAH), HR images (Sect. 3.1.), and altimetry-based water levels (Sect. 3.2.). In 2010, the emptying and refilling phases of the lake were detected accurately and reproduced by both the satellite estimates. The errors were equal to 0.20 and $0.14 \mathrm{hm}^{3}$ using the HR images and the RA-2 data, respectively. All of the altimeter-derived volumes had an error below $5 \%$ of the measured volume, whereas only half of the HR-image-based volume estimates reached 

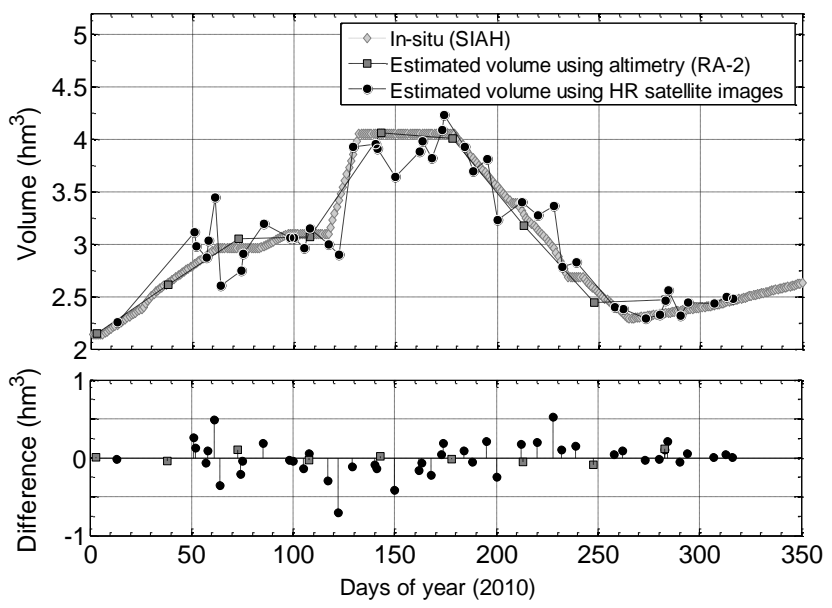

Figure 14. Comparison between volume estimates from altimeters (grey squares), HR images (black dots), and ground measurements (grey diamonds). Differences in volume estimates with in situ measurements are presented in the lower panel for both the HRBV and ABV methods.

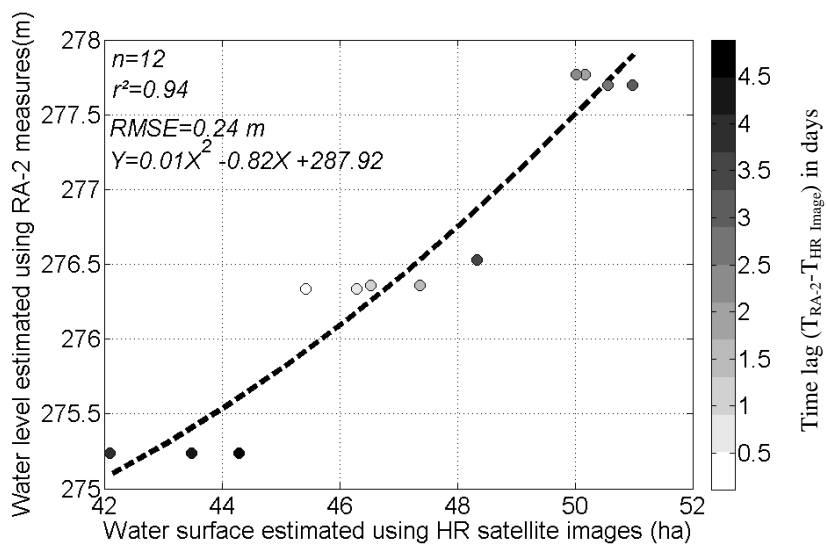

Figure 15. Relationship between satellite water surface (HR images) and water level products (altimetry) acquired with a time lag of less than five days. The grey-scale colour of each dot is used to represent the time lag observed between altimetry and imagery data.

this level of accuracy. The precision for the estimated lake volume obtained using all of the satellite products was always below $19 \%$. Figure 15 shows the relationship that was estimated between the water level obtained using the satellite products (from RA-2) and the water surface (from the HR images). Only the satellite acquisitions that were performed quasi-synchronously (for a time lag below five days) were retained to reduce the signal scatter because of the potential variation in the lake properties (i.e. the surface, level, and volume) between the images and the altimeter acquisitions. The two satellite products were strongly linearly correlated with a high coefficient of determination $\left(R^{2}=0.94\right)$.

Figure 16 shows the relationship that was obtained between the variations in the volume estimated using the

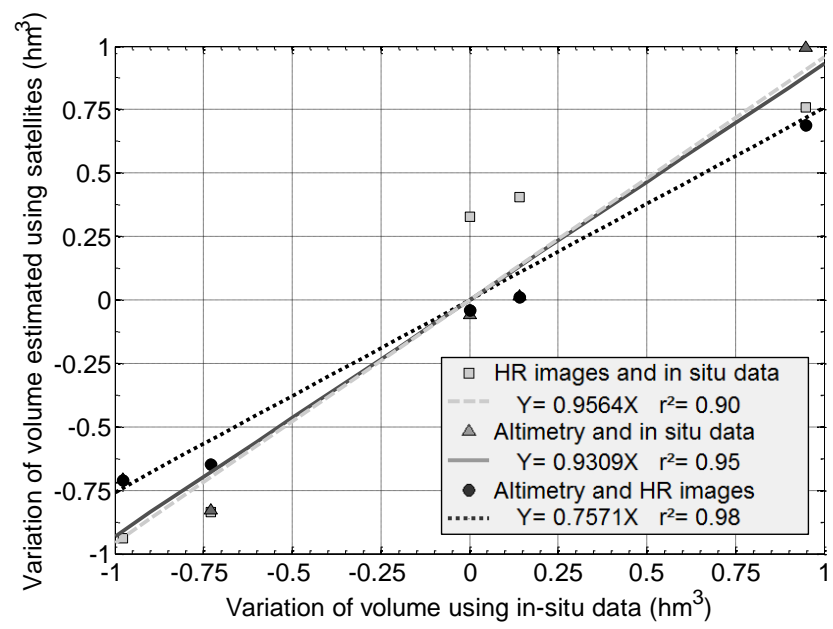

Figure 16. Comparison between the variations in the water volume estimated by satellite data (combining HR imagery and altimetry) and ground-measured (SIAH) data in 2010.

ground measurements and the satellite products. Five dates were retained in accordance with the following two constraints:

- the satellite acquisitions were performed in 2010,

- the altimetry data and HR images were acquired for a time lag of less than five days (thus implying that $\Delta V$ was less than $0.7 \%$ of the average volume during this period using the relationship between the water levels and the water volumes stored in Lake La Bure, as shown in Fig. 3).

The ground-based estimates of the variations in the water volume shown in Fig. 16 were in very good agreement with the results from this approach (i.e. $R^{2}=0.98$, $\mathrm{RMSE}=0.06 \mathrm{hm}^{3}$, and the linear regression slope was close to 1). The major drawbacks of this method are its low temporal resolution, which depends on the availability of data obtained around the same time period from both satellites, and the fact that only variations in the volume and not the volumes themselves can be determined. Figure 14 also shows the estimates of the variations in the water volume from the RA-2 altimetry-based water levels and the in situ data, and the HR images and the in situ data for the same dates. The two estimates were in very good agreement with the volume derived from the in situ data $\left(R^{2}=0.95\right.$ and RMSE $=0.17 \mathrm{hm}^{3}$ for altimetry-based volume variations and $R^{2}=0.90$ and $\mathrm{RMSE}=0.25 \mathrm{hm}^{3}$ for the HR-image-based volume variations); however, more accurate results were obtained by estimating the water volumes using altimetry and imagery. These results should be confirmed for longer time series. The results confirmed the efficacy of these products for estimating the temporal volume changes of the lake $\left(R^{2} \geq 0.90\right)$. A strong limitation of the last two relationships is that they require in situ data. 


\subsection{Discussion}

In view of improving the management of water resources, monitoring the available water volume of small lakes on regional, national or global scales is of crucial importance, but still challenging using remote-sensing technologies. The results presented in the previous sections demonstrate the potential of three approaches to provide an accurate monitoring of the volume water of a small reservoir. The HRBV and ABV methods could be applied when they are located under an altimetry track or in the field of view of HR images, and when in situ data are available (which is rare worldwide). It is worth noting that the time sampling of HR images is generally denser, allowing a more frequent survey of lakes, unlike altimeters.

Due to the lack of in situ data, the AHRBVC method will present the major interest in the coming years, even if it only provides water volume variations. Nowadays, the major drawback is the poor density of altimetry tracks at low and middle latitudes and their low temporal frequencies, as illustrated in the results of the ABV and AHRBVC methods. With the future launches of new SAR (Sentinel-3, Jason-CS) and InSAR (SWOT) altimetry and HR imagery (Sentinel-1 and Sentinel-2, Spot 7, Radarsat constellation, Alos-2) missions, these approaches are likely to be generalised to provide a more complete survey of the surface water reservoir. The interest of these new sensors is double. The first interesting point concerns the wide-swath capabilities of high-resolution imagers $(<20 \mathrm{~m})$, which allow for the monitoring of a wider continental surface (more lakes can consequently be detected during one orbit). The second point concerns the satellite altimeters. Indeed, the new generations of SAR and InSAR altimeters will provide elevation measurements in a medium or wide swath with better spatial and temporal resolutions (i.e. the same lake will be under several altimeter swaths). Lakes having a crossing with an altimeter track larger than 200 to $300 \mathrm{~m}$, and presenting variations in the water levels greater than the accuracy of the current altimeter (i.e. an annual amplitude greater than several tenths of centimetres) with a minimum surface of $\sim 0.04 \mathrm{~km}^{2}$, should be detected by both sensors. In this context, the AHRBVC method could be the easier means of collecting water volume change information on large scales. The three methods are weather independent thanks to the use of microwave data (except for multi-spectral HR images). The main factor that could restrict the use of this method is the presence of dense vegetation over the free water, which presents the use of multi-spectral images and some $\mathrm{SAR}$ at high acquisition frequencies (at $\mathrm{C}$ - and $\mathrm{X}$-bands), and degrades the radar altimetry estimates except during the high water period if the vegetation is covered with water. For most of the irrigation lakes located at middle latitudes, meteorological conditions and the density of the vegetation cover will be similar to the case of Lake La Bure. It seems very realistic to think that the three methods presented above will be transferable to other similar lakes located throughout the world.

\section{Conclusion and perspectives}

This study demonstrated the high potential of remotely sensed observations (HR images and radar altimetry) for accurately monitoring the surface volume of small lakes and reservoirs (i.e. with areas $<100$ ha). Three different approaches were developed that combined quasi-synchronous multi-satellite data and/or in situ measurements to monitor the temporal variations in water resources. All of these methods provided reliable estimates of the variations in the water volume with an average accuracy greater than $7.4 \%$ of the average volume.

In the first method, named HRBV (Sect. 4.1), the water surface estimates were converted from multispectral HR images into water volumes using in situ measurements. For our study site, this method enabled the volumes of water stored in the lake on a weekly basis to be monitored continuously. The high correlation $\left(R^{2}=0.90\right)$ was associated with a good average accuracy of $0.20 \mathrm{hm}^{3}$ (i.e. $7.4 \%$ of the average volume of Lake La Bure) of the results, thereby confirming the applicability of this method.

In the second method, named ABV (Sect. 4.2), altimetrybased (from ENVISAT RA-2) water levels were similarly combined with ground measurements to estimate the water volumes stored in the lake. This method produced more accurate estimates of the water volumes than the previous method, with an average accuracy of $0.12 \mathrm{hm}^{3}$ (i.e. $5.0 \%$ of the mean lake volume) and a coefficient of determination of 0.97 . The major drawback of this approach was the low temporal resolution (below one month) of the satellite data. These two methods cannot be generalised because they require in situ data.

Finally, in the third method, named AHRBVC (Sect. 4.3), almost-synchronous satellite estimates of water surfaces and levels were used to estimate the variations in the water volume. This approach did not require any in situ measurements and produced promising results $\left(R^{2}=0.98\right)$, which were better than those obtained using the first two approaches. However, the third method is currently limited by the poor availability of quasi-synchronous remotely sensed observations. In addition, the third method can only be used to calculate changes in the volume and cannot be used to estimate the volume itself. This latter drawback could be overcome by using lake bathymetry.

These results can be used to monitor and manage water resources, especially for agricultural purposes and even for small lakes and reservoirs. A higher spatial resolution and temporal repetitiveness allowing higher quasi-synchronous acquisitions could be achieved by using additional data from current and future satellite missions. Future launches of Sentinel-1, Sentinel-2, and Sentinel-3 will provide access to multispectral and SAR HR images combined with a dense temporal sampling (Le Roy et al., 2007; Berger et al., 2012). For radar altimetry, higher accuracy can be expected from the Saral-AltiKa mission over small water bodies because the 
footprint of the $\mathrm{Ka}$ band is smaller than that of the $\mathrm{Ku}$ band from current missions. The development of SAR-altimeter (Cryosat-2, Sentinel-3, Jason CS) and SAR-interferometry (SWOT) techniques for altimetry will densify the spatial coverage of radar altimetry over land and ocean, offering high spatial and temporal resolution (ESA Communications, 2012a, b).

Acknowledgements. The authors would like to thank CSA (the Canadian Space Agency), DLR (the German Space Agency) and ESA (the European Space Agency) for providing the Envisat, Terrasar-X, and Radarsat-2 images used in this paper (projects CSA-SOAR6828, ESA-FRBF1813, and DLR-HYD0611; F. Baup). The authors would also like to thank the Centre de Topographie des Océans et de l'Hydrosphère $(\mathrm{CTOH})$ at Laboratoire d'Etudes en Géophysique et Océanographie Spatiales (LEGOS) for providing the ENVISAT RA-2 GDR data set. The authors also thank the CNES (Centre National d'Etudes Spatiales) for funding and the CS Company for treating the Formosat-2 images. The authors thank the SIAH of the Touch for providing all of the necessary information and the lake management measurements. The authors would also like to thank Sophie Flanquart for her help with the image processing. The authors also thank W. G. M. Bastiaanssen and an anonymous referee for their constructive comments that helped us to improve the quality of the manuscript.

Edited by: A. Ghadouani

\section{References}

Abdul Hakeem, A. and Raju, P. V.: Use of high-resolution satellite data for the structural and agricultural inventory of tank irrigation systems, Int. J. Remote Sens., 30, 3613-3623, 2009.

Alsdorf, D. E., Rodríguez, E., and Lettenmaier, D. P.: Measuring surface water from space, Rev. Geophys., 45, RG2002, doi:10.1029/2006RG000197, 2007.

Baup, F., Fieuzal, R., Marais-Sicre, C., Dejoux, J. F., le Dantec, V., Mordelet, P., Claverie, M., Hagolle O., Lopes, A., Keravec, P., Ceschia, E., Mialon, A., and Kidd, R.: MCM'10: An experiment for satellite multi-sensors crop monitoring from high to low resolution observations, Geosci. Remote Sens. Symposium, IEEE International, 4849-4852, 2012.

Berger, M., Moreno, J., Johannessen, J. A., Levelt, P. F., and Hanssen, R. F.: ESA's sentinel missions in support of Earth system science, Remote Sens. Environ., 120, 84-90, 2012.

Birkett, C. M.: The contribution of TOPEX/POSEIDON to the global monitoring of climatically sensitive lakes, J. Geophys. Res., 100, 25179-25204, 1995.

Birkett, C. M.: Contribution of the TOPEX NASA radar altimeter to the global monitoring of large rivers and wetlands, Water Resour. Res., 34, 1223-1239, 1998.

Birkett, C. M., Mertes, L. A. K., Dunne, T., Costa, M. H., and Jasinski, M. J.: Surface water dynamics in the Amazon basin: Application of satellite radar altimetry, J. Geophys. Res., 107, 80598080, 2002.

Breit, H., Fritz, T., Balss, U., Lachaise, M., Niedermeier, A., and Vonavka, M.: TerraSAR-X SAR processing and products, Trans. Geosci. Remote Sens., 48, 727-740, 2010.
Brown, G. S.: The average impulse response of a rough surface and is applications, Trans. Antennas Propagation, 25, 67-74, 1977.

Calmant, S., Seyler, F., and Crétaux, J.-F.: Monitoring continental surface waters by satellite altimetry, Surveys Geophys., 29, 247269, doi:10.1007/s10712-008-9051-1, 2008.

Cazenave, A., Bonnefond, P., and Do Minh, K.: Caspian sea level from Topex/Poseidon altimetry: Level now falling, Geophys. Res. Lett., 25, 155-158, 1997.

Chern, J. S., Ling, J., and Weng, S. L.: Taiwan's second remote sensing satellite, Acta Astronaut., 63, 1305-1311, 2008.

Crétaux, J. F. and Birkett, C.: Lake studies from satellite radar altimetry, Comptes Rendus Geosci., 338, 1098-1112, 2006.

Crétaux, J.-F., Kouraev, A. V., Papa, F., Berge-Nguyen, M., Cazenave, A., Aladin, N., and S. Plotnikov, I.: Evolution of sea level of the big Aral Sea from satellite altimetry and its implications for water balance, J. Great Lakes Res., 31, 520-534, 2005.

Crétaux, J. F., Jelinski, W., Calmant, S., Kouraev, A., Vuglinski, V., Bergé Nguyen, M., Gennero, M. C., Nino, F., Del Rio, R. A., Cazenave, A., and Maisongrande, P.: SOLS: A lake database to monitor in the Near Real Time water level and storage variations from remote sensing data, Adv. Space Res., 47, 1497-1507, doi:10.1016/j.asr.2011.01.004, 2011.

Dejoux, J. F., Dedieu, G., Hagolle, O., Ducrot, D., Menaut, J. C., Ceschia, E., Baup, F., Demarez, V., Marais-Sicre, C., Kadiri, M., and Gascoin, S.: Kalideos OSR MiPy: un observatoire pour la recherche et la démonstration des applications de la télédétection à la gestion des territoires, Revue Française de Photogrammétrie et de Télédétection, 197, 17-30, 2012.

Ding, X. and Li, X.: Monitoring of the water-area variations of Lake Dongting in China with ENVISAT ASAR images, Int. J. Appl. Earth Observ. Geoinform., 13, 894-901, 2011.

Duan, Z. and Bastiaanssen, W. G. M.: Estimating water volume variations in lakes and reservoirs from four operational satellite altimetry databases and satellite imagery data, Remote Sens. Environ., 134, 403-416, doi:10.1016/j.rse.2013.03.010, 2013.

ENVI users guide: version 4.1, September, 2004.

ESA Communications: Sentinel-2: ESA's Optical High-Resolution Mission for GMES Operational Services, ESA SP-1322/2, March, 2012a.

ESA Communications: Sentinel-3: ESA's Global Land and Ocean Mission for GMES Operational Services, ESA SP-1322/3, October, $2012 b$.

ESA ENVISAT: RA2/MWR Product handbook, RA2/MWR products user guide, 2002.

Fieuzal, R., Baup, F., and Marais-Sicre, C.: Sensitivity of TERRASAR-X, RADARSAT-2 and ALOS satellite radar data to crop variables, Geosci. Remote Sens. Symposium, IEEE International, 3740-3743, 2012.

Fieuzal, R., Baup, F., and Marais-Sicre, C.: Monitoring Wheat and Rapeseed by Using Synchronous Optical and Radar Satellite Data - From Temporal Signatures to Crop Parameters Estimation, Adv. Remote Sens., 2, 162-180, doi:10.4236/ars.2013.22020, 2013.

Frappart, F., Seyler, F., Martinez, J.-M., Leon, J. G., and Cazenave, A.: Floodplain water storage in the Negro River basin estimated from microwave remote sensing of inundation area and water levels, Remote Sens. Environ., 99, 387-399, 2005. 
Frappart, F., Calmant, S., Cauhopé, M., Seyler, F., and Cazenave, A.: Preliminary results of ENVISAT RA-2-derived water levels validation over the Amazon basin, Remote Sens. Environ., 100, 252-264, doi:10.1016/j.rse.2005.10.027, 2006a.

Frappart, F., Do Minh, K., L'Hermitte, J., Cazenave, A., Ramillien, G., Le Toan, T., and Mognard-Campbell, N.: Water volume change in the lower Mekong from satellite altimetry and imagery data, Geophys. J. Int., 167, 570-584, doi:10.1111/j.1365246X.2006.03184.x, 2006b.

Frappart, F., Papa, F., Famiglietti, J. S., Prigent, C., Rossow, W. B., and Seyler, F.: Interannual variations of river water storage from a multiple satellite approach: a case study for the Rio Negro River basin, J. Geophys. Res., 113, D21104, doi:10.1029/2007JD009438, 2008.

Frappart, F., Papa, F., Santos da Silva, J., Ramillien, G., Prigent,C., Seyler, F., and Calmant, S.: Surface freshwater storage and dynamics in the Amazon basin during the 2005 exceptional drought, Environ. Res. Lett., 7, 044010, doi:10.1088/17489326/7/4/044010, 2012.

Fritz, T., Eineder, M., Mittermayer, J., Schättler, B., Balzer, W., Buckreuß, S., and Werninghaus, R.: TerraSAR-X ground segment basic product specification document, Cluster Appl. Remote Sens., TX-GS-DD-3302, 2008.

Hagolle, O., Huc, M., Pascual, D. V., and Dedieu, G.: A multitemporal method for cloud detection, applied to FORMOSAT2, VEN $\mu$ S, LANDSAT and SENTINEL-2 images, Remote Sens. Environ., 114, 1747-1755, 2010.

Haibo, Y., Zongmin, W., Hongling, Z., and Yu, G.: Water body extraction methods study based on RS and GIS, Procedia Environ. Sci., 10, 2619-2624, 2011.

Hall, A. C., Schumann, G. J. P., Bamber, J. L., and Bates, P. D.: Tracking water level changes of the Amazon Basin with spaceborne remote sensing and integration with large scale hydrodynamic modelling: A review, Phys. Chem. Earth, Parts A/B/C, 36, 223-231, 2011.

Harding, R. and Warnaars, T.: Water and global change, The WATCH Project Outreach Report, 2011.

Jorgensen, S. E., Loffer, H., Rast, W., and Straskraba, M.: Chapter 5 The use of mathematical modelling in lake and reservoir management, Develop. Water Sci., Elsevier, 54, 243-314, 2005.

Kharbouche, S. and Clavet, D.: A tool for semi-automated extraction of waterbody feature in SAR imagery, Remote Sens. Lett., 4, 381-390, 2013.

Klein, I., Dietz, A. J., Gessner, U., Galayeva, A., Myrzakhmetov, A., and Kuenzer, C.: Evaluation of seasonal water body extents in Central Asia over the past 27 years derived from mediumresolution remote sensing data, Int. J. Appl. Earth Observ. Geoinform., 26, 335-349, 2014

Küemmerle, T., Erb, K., Meyfroidt, P., Müller, D., Verburg, P. H., Estel, S., Haberl, H., Hostert, P., Jepsen, M. R., Kastner, T., Levers, C., Lindner, M., Plutzar, C., Verkerk, P. J., van der Zanden, E. H., and Reenberg, A.: Challenges and opportunities in mapping land use intensity globally, Curr. Opinion Enviro. Sustain., 5, 484-493, 2013.

Lavalle, M. and Wright, T.: Absolute radiometric and polarimetric calibration of ALOS PALSAR products, 2009

Laxon, S.: Sea ice altimeter processing scheme at the EODC, Int. J. Remote Sens., 15, 915-924, 1994.
Le Roy, Y., Deschaux-Beaume, M., Mavrocordatos, C., Aguirre, M., and Heliere, F.: SRAL SAR radar altimeter for Sentinel-3 mission, Geosci. Remote Sens. Symposium, IEEE International, 219-222, 2007.

Legrésy, B. and Rémy, F.: Surface characteristics of the Antarctic ice sheet and altimetric observations, J. Glaciol., 43, 197-206, 1997.

Lillesand, T., Kiefer, R., and Chipman J. W.: Remote Sensing and Image Interpretation, 6th Edn., John Wiley and Sons, Inc., New York, 768 pp., 2008.

Liu, C. C.: Processing of FORMOSAT-2 daily revisit imagery for site surveillance, Trans. Geosci. Remote Sens., 44, 3206-3214, 2006.

Medina, C., Gomez-Enri, J., Alonso, J. J., and Villares, P.: Water volume variations in Lake Izabal (Guatemala) from in situ measurements and ENVISAT Radar Altimeter (RA-2) and Advanced Synthetic Aperture Radar (ASAR) data products, J. Hydrol., 382, 34-48, 2010.

Michailowsky, C. I. B., McEnnis, S., Berry, P. A. M., Smith, R., and Bauer-Gottwein, P.: River monitoring from satellite radar altimetry in the Zambezi River basin, Hydrol. Earth Syst. Sci., 16, 2181-2192, doi:10.5194/hess-16-2181-2012, 2012.

Morena, L. C., James, K. V., and Beck, J.: An introduction to the RADARSAT-2 mission, Can. J. Remote Sens., 30, 221-234, 2004.

NEST (Next ESA SAR Toolbox) user manual-5.0, available at: http: //nest.array.ca/web/nest/documentation, 2013.

OECD: Water Quality and Agriculture: Meeting the Policy Challenge, OECD Studies on Water, OECD Publishing, doi:10.1787/9789264168060-en, 2012.

Richards, J. A.: Remote Sensing Digital Image Analysis, SpringerVerlag, Berlin, 240 pp., 1999.

Ricko, M., Birkett, C., Carton, J. A., and Crétaux J-F.: Intercomparison and validation of continental water level products derived from satellite radar altimetry, J. Appl. Remote Sens., 6, 061710, doi:10.1117/1.JRS.6.061710, 2012.

Sand, A. and De Boissezon, H.: Reference Remote Sensing Data Bases: Temporal series of calibrated and ortho-rectified satellite images for scientific use, 2nd International Symposium on Recent Advances in Quantitative Remote Sensing, Torrent, Spain, 2006.

Santos da Silva, J., Calmant, S., Seyler, F., Rotunno Filho, O. C., Cochonneau, G., and Mansur, W. J.: Water levels in the Amazon basin derived from the ERS 2 and ENVISAT radar altimetry missions, Remote Sens. Environ., 114, 2160-2181, doi:10.1016/j.rse.2010.04.020, 2010

Santos da Silva, J., Seyler, F., Calmant, S., Corrêa Rotuno Filho, O., Roux, E., Magalhaes, A. A., and Guyot, J.-L.: Water level dynamics of Amazon wetlands at the watershed scale by satellite altimetry, Int. J. Remote Sens., 33, 200-206, 2012.

Skriver, H., Svendsen, M. T., and Thomsen, A. G.: Multitemporal C-and L-band polarimetric signatures of crops, Trans. Geosci. Remote Sens., 37, 2413-2429, 1999.

Smith, L. C. and Pavelsky, T. M.: Remote sensing of volumetric storage changes in lakes, Earth Surf. Process. Landf., 34, 13531358, 2009. 
Strozzi, T., Wiesmann, A., Kääb, A., Joshi, S., and Mool, P.: Glacial lake mapping with very high resolution satellite SAR data, Nat. Hazards Earth Syst. Sci., 12, 2487-2498, doi:10.5194/nhess-122487-2012, 2012.

Taube, C. M.: chapter 12: Three Methods for Computing the Volume of a Lake, Annual of Fisheries Survey Methods II, 6 pp., 2000.

White, D. C. and Lewis, M.: A new approach to monitoring spatial distribution and dynamics of wetlands and associated flows of Australian Great Artesian Basin springs using QuickBird satellite imagery, J. Hydrol., 408, 140-152, 2011.

Wingham, D. J., Rapley, C. G., and Griffiths, H.: New techniques in satellite altimeter tracking systems. Proceedings of IGARSS' 86 Symposium, Ref. ESA SP-254, 1339-1344, 1986.

Yesou, H., Allenbach, B., Andreoli, R., Battiston, S., Bestault, C., Clandillon, S., and de Fraipont, P.: Synergy of High SAR and optical data for flood monitoring; the 2005-2006 Central European floods gained experience, Proceeding Envisat Symposium, 2007.
Zelli, C.: ENVISAT RA-2 advanced radar altimeter: Instrument design and pre-launch performance assessment review, Acta Astronaut., 44, 323-333, 1999.

Zhang, J. Q., Xu, K. Q., Yang, Y. H., Qi, L. H., Hayashi, S., and Watanabe, M.: Measuring water storage fluctuations in Lake Dongting, China, by Topex/Poseidon satellite altimetry, Environ. Monit. Assess., 115, 23-37, 2006.

Zhou, H., Jiang, H., Zhou, G., Song, X., Yu, S., Chang, J., and Jiang, B.: Monitoring the change of urban wetland using high spatial resolution remote sensing data, Int. J. Remote Sens., 31, 1717$1731,2010$. 